\title{
Casca de Ostra: tendências recentes dos usos ambientais visando à economia circular
}

\section{Oyster Shell: recent trends in environmental uses for circular economy}

\author{
Kelly de Araújo Rodrigues Pessoa ${ }^{1,5}$ \\ Ricardo Salgado ${ }^{1,3}$ \\ Ana Maria Alvares Tavares da Mata ${ }^{1,4}$ \\ Cristina M. Quintella ${ }^{1,2}$ \\ ${ }^{1}$ ESTS-CINEA-IPS, Instituto Politécnico de Setúbal, Portugal \\ ${ }^{2}$ IQ-UFBA, Instituto de Química, Universidade Federal da Bahia, Salvador, BA, Brasil \\ ${ }^{3}$ LAQV, REQUIMTE, Universidade Nova de Lisboa, Portugal \\ ${ }^{4} \mathrm{BBB}$ - Instituo Superior Técnico, Universidade de Lisboa, Portugal \\ ${ }^{5} \mathrm{IFCE}$, Instituto Federal do Ceará, Fortaleza, CE, Brasil
}

\begin{abstract}
Resumo
A produção de ostras em aquacultura é uma atividade econômica implantada em muitos países e que, durante o processo produtivo e o consumo, gera enormes quantidades de casca de ostra, tornando-se um resíduo importante. Este trabalho mapeia o uso ambiental desse resíduo. Realizou-se o mapeamento patentário na base Worldwide europeia, usando o software Orbit ${ }^{\circledR}$ e verificou-se que a China e a Coreia são os países com maior número de patentes. As tecnologias mais apropriadas na utilização da casca de ostra são in natura (74\%), seguida por calcinada (11\%) e por tratamentos químicos $(6,9 \%)$. Os usos ambientais frequentes compreendem o tratamento de águas residuária (32,4\%), a remoção de metais pesados (10,8\%), o tratamento de corpos de água/qualidade da água (9,5\%), o tratamento de gases $(9,1 \%)$. Os usos evidenciam que as tecnologias focam essencialmente o reaproveitamento desse resíduo como solução sustentável e potenciadora de uma economia circular.
\end{abstract}

Palavras-chave: Casca de ostra. Tratamento de águas e esgotos. Economia circular.

\begin{abstract}
The production of oysters in aquaculture is an economic activity established in many countries, and during the production process and consumption, it generates huge quantities of oyster shell, becoming an important waste. This work maps the environmental use of this waste. Patent mapping was carried out on a Worldwide European basis, using the Orbit ${ }^{\circledR}$ software, and it shows that China and Korea are the countries with the highest number of patents. The most used technologies for oyster shell are in natura (74\%), followed by calcination (11\%) and chemical treatments (6.9\%). The largest environmental uses included wastewater treatment (32.4\%), removal of heavy metals (10.8\%), treatment of water bodies/water quality $(9.5 \%)$ and gas treatment $(9.1 \%)$. The uses show that the technologies focus essentially on the reuse of this waste as a sustainable solution and enhance a circular economy.
\end{abstract}

Keywords: Oyster shell. Water treatment and sewage. Circular economy.

Área Tecnológica: Reutilização. Tecnologias ambientais. Remediação. 


\section{Introdução}

As ostras são um molusco bivalve que pode ser produzido em aquacultura, segundo diversas metodologias tecnológicas, sacos em mesas e outras, e, normalmente, em regime extensivo. Do resultado da atividade podem ocorrer mortalidades que variam de $40 \%$ a $60 \%$, dependendo do local onde são produzidas. A temperatura, as concentrações de clorofila, a biomassa de diatomáceas e as algas, potencialmente perigosas que libertam toxinas, podem levar a mortalidades elevadas (CASSIS et al., 2011). Algumas mortalidades podem também estar relacionadas com doenças causadas por ostreid herpesvirus OsHV-1, que pode atingir em alguns casos $80 \%$ a 95\% (PERNET et al., 2012). Dessa forma, são geradas grandes quantidades de casca de ostra nos locais de produção. Para além disso, quando a população consome a ostra na alimentação, são geradas também cascas de ostras. Esse subproduto da produção de ostra tende a causar impacto no ambiente se não for reutilizado.

A produção global de bivalves para consumo humano representa mais de 15 milhões de toneladas por ano (período medio de 2010 a 2015), sendo que $89 \%$ da produção de bivalves marinhos vêm da aquacultura e apenas $11 \%$ provêm das capturas selvagens. A China, em particular, é o maior produtor de bivalves com cerca de $85 \%$ da produção mundial, já que as ostras representam 4,6 milhões de toneladas por ano (2015) (SACKTON, 2018). O segundo maior país produtor é a Coreia, com 250 mil toneladas por ano. O Japão e os EUA, juntos, produziram cerca de 125 mil toneladas no ano de 2015. Na Europa, a produção tem se estabilizado ou diminuído nas últimas décadas (WIJSMAN et al., 2018). A França é o maior produtor de ostras com 100 mil toneladas no ano 2009 e 75 mil toneladas no ano de 2015 (SACKTON, 2018). Utilizando a estimativa de que em uma ostra o peso do animal corresponde a $10 \%$ ou menos do peso total, verifica-se que são gerados cerca de 5 milhões de toneladas desse resíduo anualmente. A casca de ostra constitui, assim, um importante subproduto cuja quantidade gerada não tem expectativa de diminuir no futuro, antes pelo contrário.

A concha de ostra é um resíduo que deve ter destinação correta para não ocasionar danos ambientais, problemas causados por descargas massivas no oceano (JUNG et al., 2016), assoreamento e eutrofização de baías. A disposição em terrenos, também muito observada, provoca maus odores e atrai insetos, sendo uma prática desaconselhada pelos inconvenientes causados (CHIERIGHINI et al., 2011). Para minimizar os impactes ambientais associados ao acúmulo de grandes quantidades de casca de ostra, é de extrema importância fechar o ciclo, ou seja, transformar esse resíduo em um produto com valor que acrescente de alguma forma, reintroduzindo-o na cadeia produtiva ou ambiental, promovendo, assim, o uso sustentável dos recursos naturais. Cho (2018) alerta que é preciso reduzir o impacto ambiental da casca de ostra em 50\%. Esse desígnio insere-se na economia circular que é um sistema de produção e de consumo que promove o uso sustentável dos recursos.

A casca de ostra é rica em carbonato de cálcio, podendo ser utilizada como matéria-prima em diversas indústrias, como materiais de construção, suplemento alimentar, farmacêuticos, alimentação animal, produção de plásticos, incorporado em polímeros (SILVA et al., 2018), no tratamento de águas e de águas residuárias, entre outros.

Diante de todas essas possibilidades de usos da casca de ostra em diversos campos tecnológicos e o facto de ser essencial reduzir seu impacto ambiental, de preferência melhorando as condições ambientais e com alto valor agregado, o objetivo deste trabalho é usar o mapeamento 
patentário para verificar as perspectivas e tendências mais recentes no desenvolvimento dessa tecnologia de forma a delimitar e a identificar tendências atuais e futuras do uso ambiental da casca de ostra.

\section{Metodologia}

Os documentos de patentes foram buscados na base de dados Worldwide do Escritório Europeu de Patentes (EPO), que compreende mais de 90 países. Foi utilizado o software Questel Orbit ${ }^{\circledR}$ Intelligence (Orbit 2018) no qual todos os documentos estão traduzidos para a língua inglesa.

As famílias de patentes estão baseadas na data de prioridade do primeiro depósito. Doravante, neste trabalho, será utilizado apenas o termo patente ao invés de famílias de patentes, dado que o conteúdo tecnológico é o mesmo.

Para obter as tendências recentes, foram selecionados os anos a partir de 2015, inclusive. A coleta dos dados foi realizada em 15 de maio de 2019. Foram utilizadas as palavras-chave oyster or ostreidae AND Shell nos campos de reivindicações em geral e das reivindicações independentes. Foi selecionado apenas o domínio tecnológico ambiental, conforme Schmoch (2008). Foram excluídas as patentes de corantes oyster 556 or oyster 645 e de cogumelos oyster (Tabela 1). A partir da leitura das reivindicações, foram selecionados os documentos e restou 253 que foram analisados.

Tabela 1 - Escopo do estudo, termos utilizados na busca e o número de resultados obtidos

\begin{tabular}{ccc} 
TIPO & OPERADOR & ExPRESSÃo \\
Ostra & and & oyster or ostreidae \\
$\begin{array}{c}\text { Casca de ostra } \\
\text { Domínio tecnológico: } \\
\text { tecnologias ambientais }\end{array}$ & and & Shell \\
Cogumelos & not & "mushroom" or "edible" "fungus" or "lentinus" "edode" or "lentinula" \\
Corantes & not & Edode" or "flammulina" "velutipe" or "pleurotus" "ostreatus \\
\hline
\end{tabular}

Fonte: Elaborada pelos autores deste artigo (2019)

\section{Resultados e Discussão}

A leitura dos documentos das 247 patentes focou especialmente em processo de tratamento das cascas de ostra (in natura, calcinação, tratamento térmico e/ou químico), produto final (cinzas, lascas, nanopartículas, particulado, pó, sem alteração) e uso (adsorvente, coagulante, obtenção de produtos, remoção de metais pesados e tratamento de lodos, águas, águas residuais, gases, resíduos sólidos ou solo).

A Figura 1 mostra o mapa dos países desenvolvedores de tecnologias ambientais de uso da casca de ostra, é possível observar que os detentores das tecnologias são essencialmente da Ásia. 
Figura 1 - Mapa mundial de países desenvolvedores das tecnologias ambientais de casca de ostra depositadas desde 2015

Patent families by 1st priority country (without EP and WO)

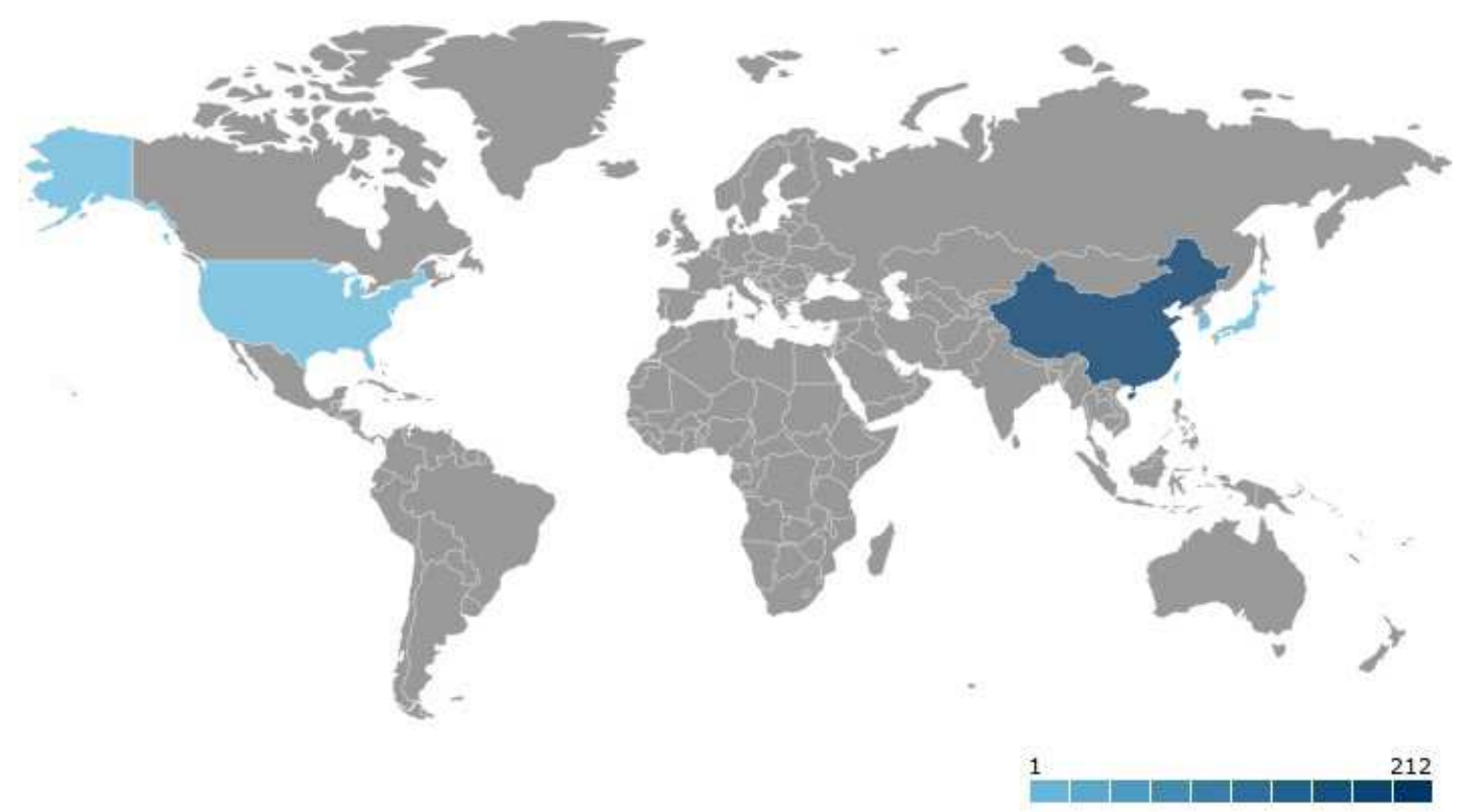

(c) Questel 2019

Fonte: Elaborada pelos autores deste artigo (2019)

O país que mais se apropria das tecnologias por meio de patentes é a China (212). Depois, em uma ordem de grandeza inferior, vem a Coreia (32), o Japão (3), Taiwan (2), os USA (2) e Singapura (1).

Apenas duas patentes foram depositadas em mais de um país. Phillips (2015) patenteou na Europa, Canadá, EUA e China, sendo titular a empresa Anua Clean Air International, um método e seu aparelho para limpar um fluxo de ar contaminado em um reator com material de revestimento de material feito a partir de conchas marinhas, com alta eficiência de limpeza de fluxo de ar contaminado, especialmente quando existem altas concentrações de sulfeto de hidrogênio e/ou enxofre orgânico, ou compostos orgânicos voláteis. Wang e Wang (2017) patentearam na China e em Taiwan, sendo titular Wang Xianzong, um modelo de utilidade de instalações de preparação de água aniônica com pelo menos uma estrutura feita de concha de ostra, a ser utilizado na infiltração de abastecimento de água.

Esse baixo número de patentes solicitadas em outros países pode ser atribuído ao fato de não haver interesse de exportação de tecnológica, de terem sido analisados apenas os anos mais recentes e pela possibilidade de o Tratado de Cooperação em Matéria de Patentes (Patent Cooperation Treaty - PCT) solicitar proteção em outros países em até 12 meses após a data da primeira prioridade.

A Figura 2 mostra os titulares com quatro ou mais patentes, sendo estes os detentores principais das patentes, podendo ser instituições de ensino, empresa ou até mesmo pessoa física. 
Figura 2 - Titulares com mais patentes de tecnologias ambientais de casca de ostra depositadas desde 2015

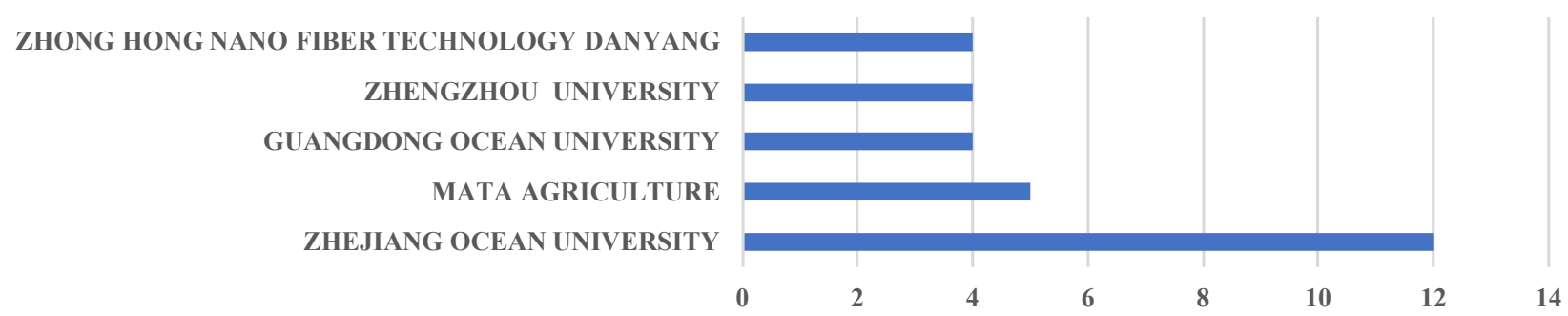

Fonte: Elaborada pelos autores deste artigo (2019)

A Zhejiang Ocean University foi a maior detentora das patentes analisadas e tem sede na cidade de Zhoushan, província de Zhejiang, na China. A instituição começou a patentear em 2003 e tem, desde então, mais de 9.400 patentes em maquinário e transportes, além de outras áreas, e patenteia apenas na China. Em casca de ostra, essa empresa tem 12 patentes sobre floculantes, microesferas, absorção de metais pesados e catalisador de degradação de xileno.

A segunda maior patenteadora foi a Fujan Mata Agriculture Development Co., uma empresa chinesa que tem 20 patentes requeridas desde 2013, principalmente na área de Engenharia Química. Suas patentes de casca de ostra estão relacionadas essencialmente a métodos e equipamentos para produzir o pó da casca. A Guangdong Ocean University, em terceiro lugar no depósito das patentes, é uma universidade recente fundada em 1997. A universidade é focada em cursos em oceanografia e ciências marítimas e está situada na cidade de Zhanjiang, província de Guangdong, na China. Essa instituição protocolou sua primeira patente em 2004 e, hoje em dia, tem mais de 1.500 depositadas, principalmente nos domínios tecnológicos de maquinários, alimentos e biotecnologia. Com casca de ostra, suas patentes são sobre tijolos ecológicos e métodos de tratamento de águas residuais.

Em quarto lugar na titularidade de patentes ficaram a Zhengzhou University e a Zhong Hong Nano Fiber Technology Danyang, sendo a primeira a maior universidade pública da China em número de estudantes e a segunda uma empresa chinesa.

A Zhengzhou University está situada na localidade chinesa de Zhengzhou, Henan, e possui patentes desde antes de 1999, em diversos domínios tecnológicos, como Engenharia Química, Engenharia Civil, materiais, metalurgia e mensuração. As suas patentes de casca de ostra são sobre sistemas para despoluição de fluxos aquosos, como rios. Já a empresa Zhong Hong Nano Fiber Technology Danyang possui cerca de 140 patentes desde 2013, principalmente relacionadas às máquinas têxteis e de papel e na área de Engenharia Química. As patentes de casca de ostra são focadas na produção de bolas de cerâmica antioxidação e em métodos de preparação de água ionizada alcalina.

Em relação aos cotitulares, observou-se que existem cinco grupos formados por chineses e coreanos:

a) Guangdong Ocean University, Shenzhen Guibao Technology e Shenzhen Institute of Guangdong Ocean University desenvolveram juntas floculantes, compósitos de quitosana e tijolos ecológicos para tratamento de águas residuais (ZHANG et al., 2017; ZHANG et al., 2018). 
b) Centre for Disease Control \& Prevention of Maoming City, Guangdong Crown Lida Marine Biological e Guangdong University of Petrochemical Technology desenvolvem filtros biológicos com casca de ostra para sistemas para fluxo sob a superfície para reoxigenação (DU et al., 2018).

c) Hangzhou Dianzi University e Zhejiang University of Science and Technology têm conjuntamente tecnologia de catalisadores contendo casca de ostra (SHENG; ZHAO, 2018).

d) Changsha Haobo Biotechnology e Qingdao Agricultural University protocolaram uma patente sobre compósitos para remediar solos contaminados com metais pesados (WANG et al., 2018).

e) Chodang University e Dongyang Plant desenvolveram um sistema poroso contendo casca de ostra para tratamento não pontual de águas residuais que serve para grandes e pequenas concentrações de poluentes (CHO, 2018).

Na Tabela 1 são mostrados os domínios tecnológicos associados às patentes de aplicação ambiental. Observa-se que a química está presente tanto em processos como em produtos químicos básicos e em macromoléculas, como a quitosana. Os domínios como maquinário, materiais e metalurgia estão associados às máquinas de moer a casca de ostra e aos produtos contendo casca de ostra.

Assim, verifica-se que a utilização de casca de ostra dentro dos domínios especificados possui amplo espectro, indo desde a sua utilização dentro da construção civil, como produto agregado às obras, à produção de fármacos, alimentos e produtos variados, além de estarem presentes no tratamento de águas, águas residuárias, resíduos orgânicos, entre outros.

A exemplo disso, no domínio da Engenharia Civil, tem-se o emprego da casca de ostra para preparo de concreto ecológico com uso de concha em pó calcinada (CHEN et al., 2015), além da construção de paredes à prova de som (CHOID, 2017) e de barreiras filtrantes ecológicas (CHEN; TAO, 2018) que retêm material sólido a montante e permitem a passagem de água e sua retenção a jusante, quando é possível seu uso para diversos fins ou benefícios.

Tabela 1 - Domínios tecnológicos associados às tecnologias ambientais de casca de ostra depositadas desde 2015

$\begin{array}{cc}\text { DomínIos TECNOLógicos } & \text { NúMERO DE PATENTES } \\ \text { Engenharia química } & 61 \\ \text { Materiais básicos de química } & 22 \\ \text { Outras máquinas especiais } & 21 \\ \text { Materiais e metalurgia } & 17 \\ \text { Biotecnologia } & 8 \\ \text { Engenharia civil } & 7 \\ \text { Polímeros de química macromolecular } & 3 \\ \text { Processos térmicos e aparelhos } & 3 \\ \text { Química de alimentos } & 2 \\ \text { Farmacêutica } & 2 \\ \text { Revestimento de tecnologia de superfície } & 1\end{array}$




$\begin{array}{cc}\text { DomínIos tecnológicos } & \text { NúMERO DE PATENTES } \\ \text { Análise de materiais biológicos } & 1 \\ \text { Elementos mecânicos } & 1 \\ \text { Transporte } & 1\end{array}$

Fonte: Elaborada pelos autores deste artigo (2019)

Dentro da indústria de fármacos, observa-se, por exemplo, a produção de um medicamento para fins de auxiliar no tratamento de lesões hepáticas, a partir do preparo de uma "água de ostra", segundo a patente depositada por Mu (2016). Em outra patente, Chen (2017) propõe o enriquecimento da casca de coco com selênio pelo seu recobrimento com mistura específica que requer pó de casca de ostra. Isso permite a produção de uma água de coco fracamente básica e mais benéfica à saúde humana, com cerca de 0,004 g de selênio por $500 \mathrm{ml}$, o que, segundo os inventores, é extremamente benéfico à saúde do corpo.

Quanto ao tratamento das cascas de ostra, as patentes foram classificadas em in natura (sem tratamento), calcinação, tratamento térmico, tratamento químico e suas associações. A Tabela 2 mostra a evolução anual das patentes para cada tratamento da casca de ostra.

Verificou-se que, de modo geral, ao longo dos anos, as maiores utilizações da matéria-prima concha de ostra ocorreram na forma in natura, representando $74,5 \%$ da forma inicialmente empregada, seguida da forma calcinada (10,9\%) e com tratamento químico (6,9\%). Já em 2018, o emprego da concha recebendo algum tipo de tratamento químico, seguido de calcinação, teve crescimento de seu emprego nos métodos propostos nas patentes avaliadas. Enquanto, no ano de 2015, não foi registrada nenhuma patente com esse tipo de processamento da matéria-prima, tanto em 2016 como em 2017, houve um aumento de 18,2\%, considerando o total de patentes avaliadas com esse tipo de processamento (11 patentes) para o período de estudo, sendo que, em 2018, o incremento foi de 63,6\%.

Considerando o total geral das 247 patentes analisadas, também os anos de 2017 e 2018 foram os que apresentaram maior registro do uso da matéria-prima concha de ostra, independentemente do tipo de processamento dado a esse material. Somente nesses anos verificou-se, respectivamente $32,4 \%$ e $28,3 \%$, a utilização da matéria-prima concha de ostra nos métodos das diferentes tecnologias constantes do total das patentes analisadas.

Tabela 2 - Evolução anual não cumulativa dos tratamentos de casca de ostra para tecnologias ambientais de patentes depositadas desde 2015

\begin{tabular}{cccccccc}
$\begin{array}{c}\text { Ano de } \\
\text { prioridade }\end{array}$ & $\begin{array}{c}\text { In } \\
\text { natura }\end{array}$ & Calcinado & Químico & Térmico & $\begin{array}{c}\text { Químico e } \\
\text { calcinado }\end{array}$ & $\begin{array}{c}\text { Químico e } \\
\text { térmico }\end{array}$ & $\begin{array}{c}\text { Total } \\
\text { anual }\end{array}$ \\
\hline 2015 & 24 & 6 & 3 & & & 2 & 35 \\
2016 & 47 & 5 & 2 & 1 & 2 & & 57 \\
2017 & 63 & 8 & 4 & 2 & 2 & 1 & 80 \\
2018 & 45 & 8 & 8 & 2 & 7 & & 70 \\
2019 & 5 & & & & & & 5 \\
Total Geral & 184 & 27 & 17 & 5 & 11 & 3 & 247
\end{tabular}

Fonte: Elaborada pelos autores deste artigo (2019) 
Não se pode deixar de mencionar que o número baixo de patentes com uso de concha de ostra como matéria-prima para usos diversos no ano de 2019 decorreu do levantamento ter sido feito ainda no quinto mês do referido ano, podendo ser que o depósito de patentes seja amplificado pela tendência observada nos dois últimos anos que o antecederam.

É importante frisar que o tratamento químico e térmico da matéria-prima em questão foi o de menor uso entre as tecnologias observadas, ressaltando-se que, geralmente, o tratamento térmico está mais relacionado à secagem do material a temperaturas de $20^{\circ} \mathrm{C}$ a $30^{\circ} \mathrm{C}(\mathrm{ZHU}$; DU, 2015) ou $200^{\circ} \mathrm{C}$ (ZHANG et al., 2017), por exemplo.

Embora o uso da concha de ostra como matéria-prima possa ser mantido sem alteração no método proposto, a concha da ostra poderá ainda ser esmagada, triturada e passar por outros processamentos até chegar à forma pretendida para uso.

Os variados tipos de processamento apresentados na Tabela 2 tiveram como fim chegar à forma desejada para aplicação na tecnologia proposta, sendo que essa forma usada, em sua maioria (68,8\%), para o período em questão, visou à obtenção do pó de casca de ostra (Tabela 3), material empregado em vários usos, isoladamente ou em mistura com outros materiais.

A Tabela 3 mostra a classificação das patentes em relação à forma final como a casca de ostra é utilizada, por ano de primeira prioridade das patentes.

Tabela 3 - Evolução anual não cumulativa da forma final da casca de ostra utilizada em tecnologias ambientais de patentes depositadas desde 2015

\begin{tabular}{ccccccc}
$\begin{array}{c}\text { Ano de } \\
\text { PRIORIDAde }\end{array}$ & $\begin{array}{c}\text { Sem } \\
\text { ALteração }\end{array}$ & Lascas & Particulado & Pó & Cinzas & Nanopartículas \\
2015 & 7 & 1 & & 26 & 1 & \\
2016 & 11 & & 7 & 39 & & \\
2017 & 15 & & 6 & 56 & & 2 \\
2018 & 19 & & 4 & 45 & & \\
2019 & & 1 & & 4 & 1 & 5 \\
Total Geral & 52 & 2 & 17 & 170 & & \\
\hline
\end{tabular}

Fonte: Elaborada pelos autores deste artigo (2019)

Em segundo lugar, destacou-se, como produto final, o emprego da casca de ostra sem alteração, ou seja, sem qualquer tipo de processamento, o que representou $21,1 \%$ da forma final para aplicação na tecnologia, entre as 247 patentes estudadas, seguida da forma particulada $(6,9 \%)$ - obtida por trituramento (TERADA et al., 2016) e/ou pela passagem em peneiras (MA et al., 2017) ou mesmo por sua liquidificação (ZHANG, 2016), como referenciado nos métodos das patentes -, em nanopartículas (2\%), lascas $(0,8 \%)(\mathrm{GU}, 2015)$ e cinzas $(0,2 \%)$ (FAN LIMIN, 2019).

O pó de casca de concha, maior produto obtido por meio das técnicas de processamento da matéria-prima, teve aplicabilidade nos anos de 2017 (33\%) e de 2018 (26\%), entre as 170 patentes em que o pó de casca de concha foi referenciado como forma final para utilização na tecnologia. Já a aplicação de casca de ostra sem alteração teve um crescente incremento de seu uso até o ano de 2018, quando representou $36 \%$ do total de 52 patentes em que foi empregada como forma final para uso na tecnologia. Com percentuais de $13 \%, 21 \%$ e $29 \%$, respectiva- 
mente, para os anos de 2015, 2016 e 2017, sendo que em 2019, até o momento presente, não houve registro de patente em que essa forma tenha sido relatada para aplicação de método.

Os usos da casca de ostra referidos nas patentes são diversos. Assim, foi feita a classificação em grandes grupos: adsorvente, coagulante, obtenção de produtos, remoção de metais pesados e tratamento de lodos, águas, águas residuais, gases, resíduos sólidos ou solo.

Apresenta-se, na Tabela 4, para cada ano desde 2015, os diversos usos da casca de ostra referidos nas patentes.

Tabela 4 - Evolução anual não cumulativa dos usos da casca de ostra utilizada em tecnologias ambientais de patentes depositadas desde 2015

$\begin{array}{cccccccc}\text { Uso } & \mathbf{2 0 1 5} & \mathbf{2 0 1 6} & \mathbf{2 0 1 7} & \mathbf{2 0 1 8} & \mathbf{2 0 1 9} & \begin{array}{c}\text { Total } \\ \text { Geral }\end{array} \\ \text { Adsorvente } & 1 & 1 & 3 & 3 & & 8 \\ \text { Coagulante } & 3 & 4 & 6 & 2 & 1 & 16 \\ \text { Disposição, tratamento e ou reaproveitamento de lodo } & 1 & & 2 & 2 & & 5 \\ \text { Obtenção de produto } & 6 & 13 & 12 & 12 & 1 & 44 \\ \text { Qualidade de água } & 2 & 7 & 10 & 4 & & 23 \\ \text { Remoção de metais pesados } & 3 & 7 & 11 & 4 & 1 & 26 \\ \text { Tratamento de água } & 1 & 3 & 4 & 5 & & 13 \\ \text { Tratamento de águas residuárias } & 14 & 13 & 20 & 29 & 2 & 78 \\ \text { Tratamento de gases } & 3 & 6 & 6 & 7 & & 22 \\ \text { Tratamento e ou disposição de resíduos sólidos } & & & 2 & & & 2 \\ \text { Tratamento ou condicionamento do solo } & & 1 & 2 & 1 & & 4\end{array}$

Fonte: Elaborada pelos autores deste artigo (2019)

O maior uso na área ambiental para a concha de ostra, entre as patentes analisadas, foi no tratamento de águas residuárias, representando 32,4\% destas. Observou-se ainda que, para esse uso, a maior parte da concha encontrava-se na forma in natura, sendo frequentemente empregada como material de enchimento de filtros biológicos e de sistemas wetlands para o tratamento de águas residuárias, ao longo dos quatro anos pesquisados.

Na patente de An et al. (2016), por exemplo, a casca de ostra é matéria-prima utilizada sem alteração como material de enchimento de um wetland. Esse tipo de sistema de tratamento faz uso de macrófitas plantadas em substrato que pode ser de um único material (camada única) ou composto de mais de um material em multicamadas. Na referida patente, a camada de substrato inferior do sistema é constituída por conchas de ostra, na qual uma de suas maiores utilidades reside na capacidade de adsorver matéria orgânica e, principalmente, nitrogênio, particularmente na forma amoniacal. Contudo, o uso de concha de ostra no tratamento de águas residuárias também é relatado para remoção de fósforo (QIN, 2016), como suporte de filtros biológico.

Ainda em relação ao tratamento de águas residuárias, o uso de concha de ostra na forma de pó, por exemplo, possui excelentes efeitos sobre o tratamento desses despejos, podendo ser empregado na remoção de compostos químicos persistentes como xileno (SONG et al., 2015) e águas residuárias com alto conteúdo químico (LU et al., 2015; TU, 2015), sendo misturado a 
outros componentes para obtenção de produto com capacidade de degradação de compostos presentes no meio.

No uso e obtenção de produtos, que representou $18,3 \%$ do total de patentes analisadas, embora tenha ocupado a segunda colocação, cabe ressaltar que envolveu variados produtos, que vão desde a bactericidas (ZHU; DU, 2015), algicidas (PARK, 2015), nanocompostos (FAN et al., 2015), técnicas de melhoria na produção de alimento (ZHANG et al., 2016), até a produção de recipientes (TAN et al., 2017), entre outros diferentes produtos. Desse modo, não foi possível juntá-los em grupos específicos por eles não possuírem características afins, ou seja, mais homogêneas.

Houve outro grande destaque do papel ecológico do emprego da casca de ostra, que foi a remediação de ambientes. Sua utilização na remoção de metais foi o terceiro uso mais proposto. Verificou-se, nesse caso, a predominância da forma final em pó, seja na remoção de metais pesados do solo ou mesmo de águas residuárias específicas, como descrito nas patentes de Zhu e Du (2015), Lai e Guan (2016) e Wang e Han (2016), por exemplo.

Outra importante aplicação verificada foi o uso da concha de ostra como agente despoluidor do meio ambiente, mais especificamente em corpos de águas, visando à remoção de nutrientes e à reversão de processo de eutrofização, sendo que seu emprego em métodos, que propõe a melhoria da qualidade de água, representou 9,5\% do total das patentes analisadas. Como exemplo, cita-se a patente de Yu et al. (2016), cuja proposta foi aplicar em rios e lagos ou reservatórios com baixa relação carbono: nitrogênio, plantas emergentes fixadas a uma matriz contendo como material de enchimento camadas de concha de ostra in natura, além de partículas de cerâmica e rochas vulcânicas. Segundo os inventores, a ação combinada desses elementos promove a purificação da água do ambiente aquático, com remoção do nitrogênio em excesso, revertendo ou minimizando a eutrofização.

Os outros usos considerados dentro da temática ambiental foram, nesta ordem, para tratamento de gases $(9,1 \%)$ - geralmente oriundos de processo de tratamento biológico de águas residuárias ou gases produzidos em processos industriais específicos; coagulante $(6,6 \%)$ - tem seu uso em conjuntos com outros componentes visando à remoção de matéria orgânica de meio aquoso (LIN, 2017; MU et al., 2017); tratamento de água (5,4\%) - como material filtrante, seja in natura (NORIKAZU, 2017) ou para produção de outro material de enchimento (SON, 2016); adsorvente (3,3\%) - adsorção de antibióticos (MA et al., 2017) e de corantes (GE et al., 2018) em meio aquoso; disposição, tratamento e ou reaproveitamento de lodo proveniente de estações de água e águas residuárias $(2,1 \%)$ - uso como agente de desidratação do lodo para diminuição de seu volume (YANG et al., 2017) ou para facilitar o emprego do lodo como matéria-prima em coprocessamento (LI et al., 2015); tratamento ou condicionamento do solo (1,7\%) - redução da biodisponibilidade de agente tóxico para plantas no solos (JING et al., 2018) e diminuição da acidez em solos (CHENG et al., 2016) para melhor crescimento e rendimento de culturas; e tratamento e ou disposição de resíduos sólidos - como um dos agentes condicionantes para reaproveitamento de resíduos sólidos da construção civil (YUSUKE; YAMAGUCHI, 2017), por exemplo.

Importa ainda mencionar que, considerando a evolução ao longo do período de estudo, descartando-se o ano de 2019, por estar em andamento, observou-se um incremento contínuo do uso voltado para o tratamento de águas residuárias de 2015 até 2018. De igual modo, houve a mesma tendência de crescimento para os usos "remoção de metais pesados" e qualidade de 
água", chegando ao ápice em 2018 (desconsiderando-se o ano de 2019, por questão já mencionada). Assim, é possível ressaltar que esses três usos são os mais preponderantes dentro do viés ambiental, abrangendo o maior número de patentes em conjunto.

Outro aspecto a ser considerado é quanto à viabilidade econômica do uso de concha de ostra nas tecnologias apresentadas. $\mathrm{O}$ estudo da viabilidade econômica dependerá do tipo de uso, da forma que será usada a concha, se in natura ou triturada ou em pó, sendo que, quanto maior o refinamento até a obtenção do pó ou farinha de ostra, maior será o investimento (PETRIELLI, 2008).

Por outro lado, o uso in natura ou triturado requer menor custo, uma vez que o uso de maquinário para processamento é pequeno ou inexistente, no caso do emprego direto da concha.

O alto teor de carbonato de cálcio presente nesse resíduo, que pode chegar a 96\% (SOUZA et al., 2015) é um estímulo para o reaproveitamento da casca de ostra, particularmente se for possível sua utilização in natura, triturada para obtenção de carbonato de cálcio, quando se requer apenas limpeza e a trituração até alcançar a granulometria desejada. Além disso, dependendo da tecnologia em que será utilizada a concha de ostra, haverá certamente grandes ganhos em termos da obtenção de sistemas eficientes e sustentáveis. Adicionalmente em termos de potenciar a economia circular, a reutilização da casca de ostra no próprio sistema de produção (aquacultura), por exemplo, para melhorar as condições ambientais do próprio local, é ainda uma oportunidade tecnológica a explorar.

\section{Considerações Finais}

O presente estudo permitiu verificar que o emprego de casca de ostra é benéfico em diversas tecnologias, promovendo aumento da eficiência em diferentes processos e na composição de materiais diversos. Observa-se ainda que a China é a maior titular em número de patentes depositadas, colocando-se também nas quatro primeiras posições em termos de titulares com mais patentes. As patentes relacionadas à área ambiental estão inseridas dentro dos domínios da Engenharia Química, Engenharia Civil e Biotecnologia, sendo que muitas tecnologias são voltadas diretamente para uso em sistemas de tratamento de águas residuárias (32,4\%), seguidas da remoção de metais pesados $(10,8 \%)$ e do tratamento de gases $(9,1 \%)$.

Embora a viabilidade econômica do uso de conchas de ostra esteja condicionada à forma na qual será aplicada, isso não diminui a importância e a necessidade de seu emprego sustentável, uma vez que representa um resíduo volumoso e que pode acarretar impactos ambientais. Dentro dessa temática, verifica-se que o emprego de casca de ostra in natura é de 74,5\% (sem tratamento térmico ou químico), e que, em termos de forma, é utilizada maioritariamente em pó $(68,8 \%)$ e o uso da casca de ostra diretamente, sem alteração é de apenas $21 \%$. Assim, a utilização da casca de ostra diretamente, sem alteração de forma, em processos ambientais deve ser reforçada, uma vez que apresenta menos custos de processamento, potenciando ao mesmo tempo a viabilidade econômica da tecnologia e a sustentabilidade do ponto de vista ecológico. 


\subsection{Perspectivas Futuras}

Percebe-se que existe um forte potencial para estudar novas possibilidades de utilização da casca de ostra com diversas aplicações nomeadamente ambientais que poderão dar resposta a uma redução do impacto ambiental desse resíduo e obter a sua valorização no âmbito da economia circular.

\section{Agradecimentos}

Os autores agradecem à Questel pelo uso do Orbit Intelligence como parte das ações do PROFNIT/FORTEC. CMQ agradece à Universidade Federal da Bahia sua liberação para capacitação docente. Kelly Rodrigues agradece ao Instituto Federal do Ceará (IFCE) sua liberação para capacitação docente. Ao projeto OSTRAQUAL - Promoção e valorização da qualidade das ostras de aquacultura nas regiões do Sado e do Mira, 023838/02/SAICT/2016, financiado pela FCT, Lisboa 2020, Alentejo 2020, CRESCAlgarve e FEDER e a toda a equipe de parceiros do Instituto Politécnico de Beja, Instituto Português do Mar e da Atmosfera e às empresas Neptunpearl, Lda, Bivalsado, Lda e Viveiros Rio Mira, Lda pelo apoio ao desenvolvimento do projeto.

\section{Referências}

AN, S. et al. F. Inventores. Nanda Research Institute. Titular. Artificial wetland matrix combination filling method. Patente chinesa CN106365319. 2016.

CASSIS, D.; PEARCE, C. M.; MALDONADO, M. T. Effects of the environment and culture depth on growth and mortality in juvenile Pacific oysters in the Strait of Georgia, British Columbia, Aquacult Environ Interact, 1: 259-274, (2011), doi: 10.3354/aei00025.

CHEN, J.; TAO, Y. Inventores. Xiamen Water Century Environmental Protection Technology. Titular. Ecological filter dam. Patente chinesa CN208732737U. 2018.

CHEN, X. Inventor. Yixing Ziyun Commerce \& Trade. Titular. Selenium-rich coconut shell liner and preparation method thereof. Patente chinesa CN107555950. 2017.

CHEN, Z. et al. Inventores. Fuzhou Royal Floor. Titular. Ecological concrete for water purification. Patente chinesa CN105645862. 2015.

CHENG, H. H. et al. Inventores. National Kangshan Agricultural, Industrial Vocational Senior High School. Titulares. Improved soil and method for improving acidic soil. Patente taiwanesaTW201803655. 2016.

CHIERIGHINI, D. et al. Possibilidade de uso de conchas de moluscos. In: $3^{\circ}$ International Workshop Advances in Cleaner Porduction. 2011. São Paulo. In: ANAIS ELETRÔNICOS DO $3^{\circ}$ INTERNATIONAL WORKSHOP ADVANCES IN CLEANER PRODUCTION. São Paulo, Brasil, 2011. Anais [...], Brasil, 2011. Disponível em: http://www.advancesincleanerproduction.net/third/files/ sessoes/6A/6/Chierighini_D\%20-\%20Paper\%20-\%206A6.pdf. Acesso em: 4 set. 2019. 
CHO, G. A. Inventor. Chodang University, Dongyang Plant. Titulares. Porous carrier for nonpoint pollution source treatment and manufacturing method thereof. Patente coreana KR20180111045. 2018.

CHOI, D. Y. Inventor. Shinyoung Technology. Titular. Noise barrier structure for transparent panel assemble. Patente coreana KR101936775. 2017.

DU, C.; YU, Z.; XIAO, M. Inventores. Centre for Disease Control \& Prevention of Maoming City, Guangdong Crown Lida Marine Biological, Guangdong University of Petrochemical Technology. Titulares. Reoxygenation type subsurface flow constructed wetland. Patente chinesa CN107935190. 2018.

FAN, L. Inventor. Fujian Lihang Construction. Titular. Artificial wetland ecological waste water treatment system. Patente chinesa CN109574240, 2019.

FAN, L. et al. Inventores. Fujian Agriculture, Forestry University. Titulares. Nano iron/oyster shell composite material, and preparation method and application thereof. Patente chinesa CN104549126. 2015.

GE, H. et al. Inventores. Dalian University for Ntionalities. Titular. Preparation method and application of dye adsorbent based on shell powder. Patente chinesa CN108114690. 2018.

GU, J. J. Inventor. Je Jin Gu. Titular. Stationary phase carrier for wastewater treatment. Patente coreana KR20160101354. 2015.

JING, J.; ZHANG, Z.; WANG, Z. Inventores. Beijing Junmei Environmental Technology. Titular. Soil passivator with function of reducing bioavailable cadmium in soil and methods for preparing and applying soil passivator. Patente chinesa CN108559521. 2018.

JUNG, S. et al. Feasibility test of waste oyster shell powder for water treatment. Process Safety and Environmental Protection, [S.I.], v. 102, p. 129-139, 2016. DOI: 10.1016/j.psep.2016.03.004.

LAI, P.; GUAN, T. Inventores. Sichuan Xinlong Agricultural Science \& Technology. Titular. Remediation method for soil contaminated by heavy metal. Patente chinesa CN105772500. 2016.

LI, B. et al. Inventores. Huaqiao University. Titular. Method for promoting quality of oil pyrolyzed from sludge. Patente chinesa CN105295981. 2015.

LIN, C. Inventor. Foshan Zaodaotian Environmental Protection Energy Saving Technology. Titular. Environment-friendly biological compound sewage treatment agent. Patente chinesa CN107935153. 2017.

LU, S. Inventores. Yancheng Ouhua Chemical Industry. Titular. Chemical industry wastewater treatment agent. Patente chinesa CN106477637. 2015.

MA, X. Inventores. Ludong University. Titular. Oyster shell adsorbent as well as preparation method and application thereof. Patente chinesa CN107442075. 2017.

MO, K. H. Recycling of seashell waste in concrete: a review. Construction and Building Materials, v. 162, 751-764, 2018. doi:10.1016/j.conbuildmat.2017.12.009.

MU J. et al. Inventores. Zhejiang Ocean University. Titular. Method for preparing ecological bionic microbial flocculant from leftovers of marine products. Patente chinesa CN107089712. 2017.

MU, X. Inventor. Mu Xuefeng. Titular. Preparation method of oyster water. Patente chinesa CN106186468. 2016. 
NORIKAZU, K. Inventor. Shell Touch. Titular. Water treatment apparatus. Patente japonesa JP2019034295. 2017.

PARK, S. I. Inventor. Su Ill Park. Titular. The Natural Removal Materials of Green Bloom and the Method of Production. Patente coreana KR20170031421. 2015.

PERNET, F. et al. Mass mortalities of Pacific oysters Crassostrea gigas reflect infectious diseases and vary with farming practices in the Mediterranean Thau lagoon, France. Aquacult Environ Interact, [S.l.], v. 2, p. 215-237, 2012. doi: 10.3354/aei00041.

PETRIELLI, F. A. S. Viabilidade técnica e econômica da utilização comercial de conchas de ostras descartadas na localidade de Ribeirão da Ilha, Florianópolis, Santa Catarina. 2008. 125f. Dissertação (Mestrado em Engenharia Ambiental) - Universidade Federal de Santa Catarina, UFSC, Florianópolis, 2008.

PHILLIPS, J. P. Inventor. Anua Clean Air International. Titular. A method and apparatus for cleaning a contaminated air stream in a reactor with marine shell material. Patente europeia EP3175908. 2015.

QIN, L. Inventor. Guangxi University. Titular. Multilayer sewage treatment device. Patente chinesa CN106116065. 2016.

RICE, M.A. Environmental Impacts of Shellfish Aquaculture: Filter Feeding to Control Eutrophication. Environment Cape Cod., [S.I.], v. 1, n. 1, p. 77-86, 2000.

\section{SACKTON, J. Outlook for Oysters in the US Market and Beyond, Seafood Data search} Summerside, PEI February 22, 2018.

$\mathrm{SCHMOCH}$, U. Concept of a Technology Classification for Country Comparisons. Anexo 41a Session da Committee of Experts da Special Union for the International Patent Classification (IPC Union), World Intellectual Property Organization (WIPO), IPC/CE/41/5. 2008. Disponível em https:// www.wipo.int/edocs/mdocs/classifications/en/ipc_ce_41/ipc_ce_41_5-annex1.pdf. Acesso e, 03/ jun/2019.

SHENG, W.; ZHAO, X. Inventores. Hangzhou Dianzi University e Zhejiang University of Science and Technology. Titulares. Composite photocatalyst shell-based boron-doped titanium dioxide and preparation method thereof. Patente chinesa CN108325547. 2018.

SILVA, T. H. et al. The Potential Use of Oyster Shell Waste in New Value-Added By-Product. Resources, [S.I.], v. 8, n. 13, p. 1-15, 2018. doi:10.3390/resources8010013.

SON, H. J. Inventor. Woori Engineering. Titular. Non-point sources including rainwater treatment system. Patente coreana KR101682581. 2016.

SONG, W. et al. Inventores. Zhejiang Ocean University. Titulares. Method for preparing xylene degradation catalyst from shell powder and titanium dioxide. Patente chinesa CN105268421. 2105.

SOUZA, A. B. B. et al. Viabilidade econômica e ambiental do uso de conchas e mariscos: estudo de caso na comunidade de nossa senhora do livramento, Paraíba. In: XXXV Encontro Nacional de Engenharia de Produção. 2015. Fortaleza. Anais eletrônico do XXXV Encontro Nacional de Engenharia de Produção. Fortaleza, Ceará, Brasil. Disponível em: http://www.abepro.org.br/ biblioteca/TN_STO_214_266_28392.pdf. Acesso em: 4 set. 2019.

TAN, B. et al. Inventores. Chongqing Keyunrui New Material. Glass steel dustbin with base plate and producing method thereof. Patente chinesa. CN107215595. 2017. 
TERADA, S. et al. Inventores. Hirai Kogyo. Titular. Process for the removal of phosphous in wastewater by using oystershell and appratus thereof. Patente coreana KR101730492. 2016.

TU, G. Inventor. Jiangsu Jihua Chemical. Titular. Cleaning agent for chemical wastewater. Patente chinesa CN106698532. 2015.

WANG, M.; HAN, H. Inventores. Jining University. Titular. Microorganism water treatment agent for heavy metal organic wastewater. Patente chinesa CN106007006. 2016.

WANG, K.; SONG, N.; ZHANG, H. Inventores. Changsha Haobo Biotechnology, Qingdao Agricultural University. Titulares. Composite repair agent for soil heavy metal pollution and application thereof. Patente chinesa CN108085010B. 2018.

WANG, X.; WANG, M. Inventores. Wang Xianzong. Titular. Anion water 's preparation facilities. Patente chinesa CN206666401. 2017.

WIJSMAN, J. W. M. et al. Global Production of Marine Bivalves. Trends and Challenges, Goods and Services of Marine Bivalves, p. 7-26, 2018, doi.org/10.1007/978-3-319-96776-9_28.

YANG, Q. et al. Inventores. Foshan Ironman Environmental Protection Technology. Titular. Sludge dewatering agent and preparation method and dewatering method thereof. Patente chinesa CN108002675. 2017.

YU, L. et al. Inventores. Zhengzhou University. Titular. Ecological floating bed device for in-situ enhanced denitrification of micro-polluted river. Patente chinesa CN106396121. 2016.

YUSUKE M.; YAMAGUCHI, M. Inventores. Yoshino Gypsum. Titular. Method for producing reproduced waste material composition and reproduced waste material composition. Patente japonesa JP2019006672. 2017.

ZHANG, C. et al. Inventores. Henan University of Science \& Technology. Titular. Efficient fishery water quality improver as well as preparation method and application thereof. Patente chinesa CN107555611. 2017.

ZHANG, R. Inventor. Zhang Rui. Titular. Ecological environment-friendly desulfurizer and preparation method thereof. Patente chinesa CN105833711. 2016.

ZHANG, R. et al. Inventores. Guangdong Ocean University, Shenzhen Guibao Technology, Shenzhen Institute of Guangdong Ocean University. Titulares. Natural zwitterionic composite wastewater treatment flocculant and its application method. Patente chinesa CN109678235. 2017.

ZHANG, R. et al. Inventores. Guangdong Ocean University, Shenzhen Guibao Technology, Shenzhen Institute of Guangdong Ocean University. Titulares. Biological flocculant environment friendly composite wastewater, treating contaminated water bacteriostatic agent. Patente chinesa CN109292924. 2018.

ZHANG, Z. et al. Inventores. Hengmao Industry. Titular. Aquaculture nutrition sustained release agent and preparation method thereof. Patente chinesa CN106278769. 2016.

ZHU, L.; DU, Y. Inventores. University of Nankai. Titular. Method for treating heavy metal ion wastewater with modified shell powder. Patente chinesa CN105561912. 2015. 


\section{Sobre os Autores}

\section{Kelly de Araújo Rodrigues Pessoa}

E-mail: kellyarpessoa@gmail.com

Doutorado em Hidráulica e Saneamento.

Endereço profissional: Instituto Federal do Ceará (IFCE), Campus Fortaleza, Avenida Treze de Maio, n. 2.081,

Benfica, Fortaleza, Ceará. CEP: 6000-000.

\section{Ricardo Salgado}

E-mail: ricardo.salgado@estsetubal.ips.pt

Doutorado em Engenharia Química e Bioquímica.

Endereço profissional: ESTSetúbal/IPS, Campus, IPS, Estefanilha, Setúbal, Portugal. CEP: 2910-761.

\section{Ana Maria Alvares Tavares da Mata}

E-mail: ana.mata@estsetubal.ips.pt

Doutorada em Engenharia do Ambiente.

Endereço profissional: ESTSetúbal/IPS, Campus, IPS, Estefanilha, Setúbal, Portugal. CEP: 2910-761.

\section{Cristina M. Quintella}

E-mail: cris5000tina@gmail.com

Doutorada em Ciencias Moleculares.

Endereço profissional: IQ-UFBA, Instituto de Química, Universidade Federal da Bahia, Campos de Ondina, Salvador, BA. CEP: 40170-115. 